Article

\title{
Ideyolohiya at Utopia sa mga Liham sa Ina ng Laging Saklolo sa Baclaran
}

\section{Jennifer M. Casabuena}

\begin{abstract}
This paper is focused on examining the contents of the letters addressed to Our Lady of Perpetual Help based on the level and shape of ideology and utopia. The following is the task of this piece: to determine the devotees' concept of devotion, to ascertain the manner by which the devotees exercise their devotion to the Our Lady of Perpetual Help, and, to highlight the implication of ideology and utopia contained within the letters in relation to talks about conversion and societal transformations. Using the observations and interviews gathered from 96 respondents, this researcher was able to illustrate the manner by which the devotees practice their devotion. A sum of 215 letters were used to determine the level and shape of ideology and utopia prevailing in these letters. Based from the result of the studies, there are different concrete practices that the Filipino devotees do in relation to their devotion to Mary. In the field of ideology, what prevails is the devotees' wish to be cured from their sickness, financial help, and reconciliation - these are the primary ideological aspects contained within the letters which blinds the devotees. On the other hand, in the field of utopia, we may discover the dominant concrete utopic visions in the letters about spiritual grace, health and recovery from non-threatening ailments, passing exams and obtaining jobs. This utopia can be seen as a result of the movement of the devotees including their practices of praying in order to ask for their wishes to be granted. As a result, it appears that the realization of their wishes brings about the deepening of their faith, changes in attitude and behavior, trust in God, and deeper devotion. As a conclusion for this study, this researcher has discovered that the Filipino way of true devotion and dealing with Mary occurs in one process: experience of challenges, visitation, participation, act of mutual trust, and being one with others.
\end{abstract}

Keywords: Our Lady of Perpetual Help, letters, ideology, utopia

(c) 2015 Jennifer M. Casabuena

http://www.kritike.org/journal/issue 17/casabuena december2015.pdf

ISSN 1908-7330

$(c c)$ BY-NC-ND 


\section{Introduksyon}

S a kasalukuyan, ang Baclaran ang nagsisilbing saksi sa malalim na debosyon ng mga Pilipinong Katoliko sa imahen ng Ina ng Laging Saklolo. Ipinapakita ng Baclaran phenomenon ang napakaraming bilang ng mga taong nagpupunta sa Baclaran tuwing araw ng Miyerkules para sa nobena sa Ina ng Laging Saklolo. Isa sa natatanging gawain ng pagnonobena sa Mahal na Birhen ang pagbabasa ng mga liham ng pasasalamat. Ang mga liham pasasalamat sa mga kahilingang natatanggap ay mga konkretong patunay ng malalim na pamimintuho kay Maria. Ito ay paglalarawan ng matinding pagsandig ng mga Pilipino sa kanilang pananampalataya para sa kanilang pangangailangan. Ang mga liham na inihuhulog ng mga deboto para kay Maria ay isang halimbawa ng kanilang paniniwala at pag-asa sa kaganapan ng kanilang mga kahilingan.

Ang pag-aaral na ito ay nakatuon sa pagsusuri ng penomenon ng pagsulat ng liham ng mga deboto sa Ina ng Laging Saklolo. Naglalayon itong ilarawan ang gawain ng paghuhulog ng liham sa dambana ng Ina ng Laging Saklolo sa Baclaran gayundin ang matukoy ang hugis at antas ng ideyolohiya at utopia na mayroon ang mga mananampalatayang Katoliko na makikita sa mga liham na kanilang inihulog sa nasabing dambana. Sa pamamagitan ng pag-aaral na ito, malalaman kung alin sa ideyolohiya at utopia ang nangingibabaw sa mga liham ng mga deboto. Gagamiting salalayan sa pagaaral na ito ang mga teorya nina Mannheim at Bloch ukol sa ideyolohiya at utopia.

\section{Metodolohiya}

Dalawa ang datos na sinuri ng mananaliksik na magsisilbing sagot sa layunin ng kaniyang pag-aaral. Una na rito ay ang panayam sa 96 na mga deboto at pangalawa, ang mga liham ng mga deboto sa Ina ng Laging Saklolo sa buwan ng Mayo taong 2014.

Sa 2,292 liham (petisyon at pasasalamat) ng mga deboto sa Ina ng Laging Saklolo sa Baclaran, mayroong 207 liham pasasalamat at 2,085 na petisyon o kahilingan. Mula sa bilang na ito ng mga liham, pinili ang 215 na huwarang mga sipi ng liham upang kumatawan sa pagsusuri ng antas at hugis ng ideyolohiya at utopia. Sa pagsusuri ng mga liham na ito gumamit ng coding ang mananaliksik. Ginamit ang D1-D215 para kumatawan sa mga halimbawang liham na ginamit sa pagsusuri. Samantala ang K1-K18 naman ay kumakatawan sa 18 kategorya kung saan inuri ang kahilingan ng mga deboto sa mga liham batay sa:

(C) 2015 Jennifer M. Casabuena http://www.kritike.org/journal/issue 17/casabuena december2015.pdf ISSN 1908-7330

(c) BY-NC-ND 
K1: Espiritwal na Biyaya

K2: Pagbabalik-loob

K3: Kapayapaan sa Tahanan

K4: Pagkakasundo

K5: Katuwang sa Buhay

K6: Kalusugan at Paggaling

K7: Kaligtasan sa Sakuna

K8: Pagkakaroon ng Anak

K9: Tulong Pinansyal
K10: Tagumpay sa Pag-aaral

K11: Pagpasa sa Eksam,

K12: Pagbyahe sa Ibang Bansa

K13: Pagkakaroon ng Trabaho

K14: Katarungan at Kapayapaang

Panlipunan

K15: Legal na Biyaya

K16: Materyal na Biyaya

K17: Lahat ng Biyaya

K18: Pasasalamat

Teorya naman nina Karl Mannheim at Ernst Bloch ang ginamit na lente para sa paghimay sa mga datos na ito. Si Karl Mannheim ay kilalang sosyolohista at pilosopo na ipinanganak sa Hungary. Ang kanyang sosyolohiya ng kaalaman ang nagpalawak sa pananaw ni Karl Marx hinggil sa magkaibang sistema ng paniniwala ng proletaryo at ng burgis. Sa pananaw ni Mannheim ang salungatang panlipunan ay bunga ng magkakaibang ideyolohiya mula sa iba't ibang antas ng lipunan. Ginamit niya ang konsepto ng ideyolohiya at utopia bilang dalawang pangunahing kaisipang lumilinlang sa diskursong politikal. Ninais niyang alisin ang negatibong katangian ng dalawang konseptong ito at gamitin ito bilang batayan sa pagunawa kung paanong tinitingnan ng ilang grupong panlipunan ang kanilang kapaligiran. ${ }^{1}$

Naniniwala siya na ang ideyolohiya ay makikita saanman at walang aspekto ng buhay ng tao na hindi napapalamutian ng ideyolohiya. Ang mga ideyolohiyang ito ay nakatago at kinakailangang tanggalin ang maskarang bumabalot sa ideyolohiya ng tao tulad ng pagtatanggal ng kasinungalingan. Hinahanap niya ang reyalidad sa likod ng ideyolohiya at utopia. Katulad ng pananaw ni Marx, ang pananaw ni Mannheim sa ideyolohiyang ito ay pumipigil sa anumang pagtatangka sa pagbabago samantalang ang utopia naman ay mayroong paghahangad sa pagbabago upang mapabuti ang kanilang estado kaya naman kinakailangang buhayin ang utopia sapagkat taglay nito ang kinakailangang pagbabagong panlipunan. ${ }^{2}$

Ang ideyolohiya ay mga ideya na hindi natamo ang katotohanan sa pagsasakatuparan nito ayon sa kanilang nilalaman. Ang mga ideyolohiya ay maituturing na mga mabubuting layunin para sa subhetibong pagkilos ng indibiwal. Kapag ang mga ideyolohiyang ito ay inilalangkap sa pagkilos ng

\footnotetext{
${ }^{1}$ See Lyman T. Sargent, "Utopianism" in Index, Vol. 10 of Routledge Encyclopedia of Philosophy, ed. by Edward Craig (London: Routledge, 1998), 558.

2 See Lyman T. Sargent, "Ideology and Utopia: Karl Mannheim and Paul Ricoeur," in Journal of Political Ideologies, 13:3 (2008), 266-267.
}

(C) 2015 Jennifer M. Casabuena http://www.kritike.org/journal/issue 17/casabuena december2015.pdf ISSN 1908-7330 
indibidwal, ang kahulugan nito kadalasan ay kabaliktaran. Ipinakita ito sa turo ng Kristyanismo ukol sa pagmamahal sa kapwa sa isang lipunang mayroong pang-aalipin. Bagamat itinuturo ng simbahan ang pagmamahal sa kapwa, namamayani pa rin ang pang-aalipin sa mga nakararaming manggagawa sa ganitong aspekto. Masasabing ideyolohikal na ideya ang konsepto ng pagmamahal sa kapwa at hindi pa rin ito natatamo kung ang lipunan ay hindi naayos ayon sa prinsipyo na itinuturo ng simbahan. Sapagkat ang ideyolohikal na pagkilos ay kadalasang hindi umaayon sa nais nitong ipakahulugan, nakabuo si Manhheim ng mga anyo ng ideyolohiya. ${ }^{3}$

Tinalakay din ni Mannheim sa kaniyang pag-aaral ng ideyolohiya ang tatlong pangunahing uri ng ideyolohikal na elemento: 1) ang mga elementong pumipigil sa mga tao na makita ang hindi pagkakatugma ng ideyolohiya at reyalidad, 2) ang elementong nag-uudyok sa isang tao para linlangin niya ang kaniyang sarili at magbulag-bulagan sa harap ng mga panlipunang kontradiksyon, at 3) panlilinlang ng isang tao sa kaniyang kapwa para tanggapin na lamang nito ang umiiral na kaayusan kahit gaano man ito kamapang-api at hindi pantay-pantay. ${ }^{4}$

Sa kabilang banda, ang konsepto ng utopia ni Mannheim ay isang manipestasyon ng kamalayang salungat sa ideyolohiya. Ito ay nakatuon sa mga bagay na hindi umiiral sa tunay na buhay; ito ay lampas sa katotohanan o walang katotohanan. ${ }^{5}$ Ang pakahulugan niya ng utopia ay anumang proseso ng kaisipan na tumatanggap ng istimulus hindi mula sa reyalidad kundi mula sa konsepto ng simbolo, pantasya, panaginip, ideya-sa madaling salita, mga bagay na hindi naman talaga umiiral. Para sa kanya, ang dalawang kaisipang ito ay ideyolohikal kapag mayroong panlilinlang sa reyalidad panlipunan at utopian naman kapag nilalayong baguhin ang reyalidad upang umayon sa kanilang mithiin na maaring lumampas sa reyalidad. ${ }^{6}$ Nagiging utopia lamang ang mga ideyolohiya kapag ang mga pangarap na ito ay inilangkap na nila sa kanilang mga aktwal na gawain at sinikap na maisakatuparan ito.

Hindi tinanggap ni Bloch ang estratehiya ni Mannheim sa paggamit ng kasaysayan upang makabuo ng balangkas ng ideyolohiya at utopia sapagkat para kay Mannheim, itinuturing na ilusyon (wishful thinking) lamang lahat ng anyo ng mga pag-asang hindi nagiging aktibong utopia. Sa

\footnotetext{
${ }^{3}$ See Karl Mannheim, Ideology and Utopia: An Introduction to the Sociology of Knowledge (London: Routledge and Kegan Paul, Ltd., 1960), 174-175.

4 See Feorillo Petronillo A. Demeterio, III, "Mga Anyo at Antas ng Pag-asa na Nakapaloob sa mga Diskurso ng El Shaddai," in Malay, 22:2 (2010): 19-43.

${ }^{5}$ See Eduard Batalov, The American Utopia (Moscow: Progress Publishers, 1985), 9.

${ }^{6}$ See Sargent, "Utopianism," 558.

(c) 2015 Jennifer M. Casabuena

http://www.kritike.org/journal/issue 17/casabuena december2015.pdf

ISSN 1908-7330

(cc) BY-NC-ND
} 
pananaw naman ni Bloch, lahat ng mga pag-asa at pangako ay mayroong himaymay ng tinatawag niyang utopian surplus. ${ }^{7}$

Para kay Bloch, ang pag-asa ay laganap sa araw-araw na kamalayan ng tao at malinaw na makikita sa iba't ibang anyo ng kultura ng tao simula sa mga "fairy tale" tungo sa mga pilosopikal at politikal na utopia. Ang bawat indibidwal ay mayroong mga pangarap na inaasam niyang makamit. Naniniwala si Bloch na mayroong mga hindi nakakamit na potensyal na nangangailangan ng pagbabagong panlipunan na nangangahulugan lamang na mayroong utopia sa lahat ng sitwasyong nararanasan ng tao. Ang utopia ay abot-tanaw lamang, hindi pa nakakamit, at mayroong posibilidad na makamit. Ang mga hangarin at pag-asa ng tao ay matatamo upang magkaroon ng isang maayos na pamumuhay ang tao. Naniniwala si Bloch na ang mga tao ay aktibong kalahok sa pagbuo ng isang magandang hinaharap; kailangan lamang ng taong mag-isip at kumilos ayon sa bisyong nakita ni Bloch sa sining, literatura, at musika. ${ }^{8}$

Sa kaniyang konsepto ng utopianismo, ginamit niya ang abstrak at konkretong utopia. Ang abstrak na utopia ay makikita sa pinakamahina nitong anyo na nangangahulugang pagnanasa lamang at walang malinaw na balangkas kung paano ito matatamo. Samantalang ang konkretong utopia naman ay isang obhektibong posibilidad na kung saan mayroong pagmimithi ng kaganapan ang kanilang pangarap na nakabatay sa masinsinang pag-aaral ng umiiral na kaayusan at pulidong pagdalumat ng balangkas at metodo ng pagbabago. ${ }^{9}$

Gamit ang teorya ni Mannheim, inilahad ng mananaliksik ang antas at hugis ng ideyolohiya na nangingibabaw sa mga inihulog na liham ng mga deboto sa Dambana ng Ina ng Laging Saklolo sa Baclaran upang matukoy ang implikasyon ng ideyolohiyang nakapaloob sa mga liham na ito sa usapin ng pagbabagong-loob at pagbabago ng lipunan.

Pagtutuunan ng pansin sa pagsusuring ito ang tatlong pangunahing uri ng ideyolohiyang nabuo ni Mannheim. : 1) mga elementong pumipigil sa isang taong makita niya ang tunay na kaayusan ng reyalidad, 2) mga elementong nag-uudyok sa isang taong linlangin niya ang kaniyang sarili hinggil sa tunay na kaayusan ng reyalidad, at 3) panlilinlang ng isang tao sa kaniyang kapwa para tanggapin na lamang ang umiiral na kaayusan.

Samantala, gamit naman ang teorya ni Bloch, sinuri ng mananaliksik kung gaano kaabstrakto o kakonkreto ang mga pagmimithi/pag-asang mayroon ang mga deboto mula sa mga liham na kanilang inihulog sa

\footnotetext{
${ }^{7}$ See Vincent Geoghegan, "Ideology and Utopia," in Journal of Political Ideologies, 9:2 (2004), 128

8 See Sargent, “Utopianism," 560.

${ }^{9}$ See Demeterio, "Mga Anyo at Antas ng Pag-asa na Nakapaloob sa mga Diskurso ng El Shaddai," 24.
}

(c) 2015 Jennifer M. Casabuena http://www.kritike.org/journal/issue 17/casabuena december2015.pdf ISSN 1908-7330 
dambana ng Ina ng Laging Saklolo. Nais makita ng mananaliksik kung gaano kakonkreto sa parte ng mga deboto at kung gaano kalakas ang kanilang pagmimithi upang maisakatuparan ang kanilang mga inaasam.

\section{Resulta at Diskusyon ng Pag-aaral}

\section{Paglalarawan ng Debosyon sa Ina ng Laging Saklolo sa Baclaran}

Sa paraan ng pagdedebosyon ng mga deboto sa Ina ng Laging Saklolo natuklasan ng mananaliksik na marami sa mga deboto ang nagsimula ang debosyon dahil sa impluwensya ng kanilang kapamilya, partikular na ang kanilang lola o ina. Naging tradisyon na ng pamilya ang pagnonobena sa Ina ng Laging Saklolo kaya nahihikayat na rin ang kapamilya na gawin ito. Mayroon din namang ang nakakaimpluwensya sa kanila para magnobena at maging deboto ay ang kanilang mga kaibigan. Sa bihirang pagkakataon, mayroong ilan na dahil naririnig na nila ang pangalang Ina ng Laging Saklolo at ang mga himala nito kaya sila na mismo ang pumupunta sa dambana upang humingi ng tulong lalo na sa panahon ng matinding pangangailangan.

Kaugnay ng kanilang gawain bilang tanda ng kanilang debosyon sa Ina ng Laging Saklolo, lumabas na ang mga sumusunod naman ang kanilang ginagawa: pagnonobena, pagtanod kapag araw ng Martes, paglalakad nang paluhod, pagsalat sa imahen ng Ina ng Laging Saklolo, pagdarasal ng Santo Rosaryo, boluntaryong paglilingkod sa Dambana ng Ina ng Laging Saklolo at paghuhulog ng liham sa dambana.

Ayon sa mga deboto, ang mga pangunahin nilang dahilan sa pagdedebosyon ay pagtupad ng Mahal na Ina sa kanilang mga kahilingan, bilang pasasalamat sa biyayang natatanggap, at naging bahagi na si Maria ng kanilang buhay. Dahil naman sa kanilang pagnonobena, mayroon ding kabutihang naidudulot ito sa kanila tulad ng pag-iwas sa kanilang masasamang bisyo, nagiging matapang sa pagharap sa pagsubok, at pagbabago ng ugali. Dahil din sa kanilang pagiging deboto at palagiang pagnonobena sa Ina ng Laging Saklolo, nagiging magaan ang kanilang pakiramdam kahit na marami silang mga problema sa buhay. Mula rin sa mga nakapanayam, natuklaasan na ang mga hinihiling nila ay may kaugnayan sa kalusugan, trabaho, pagkakaroon ng anak o katuwang sa buhay, at pagpasa sa eksam.

\section{Antas at Hugis ng Ideyolohiya sa mga Liham}

Malaki ang kaugnayan ng pananampalataya ng mga Pilipino sa kanilang paghingi ng tulong kay Maria. Kadalasang makikita sa mga liham

(c) 2015 Jennifer M. Casabuena

http://www.kritike.org/journal/issue 17/casabuena december2015.pdf

ISSN 1908-7330

(c) $)$ BY-NC-ND 
ng mga deboto sa Ina ng Laging Saklolo ang kanilang paniniwala na ang anumang kanilang hilingin ay kanilang matatamo o ibibigay sa kanila sapagkat hindi sila kayang biguin ni Maria. Ayon sa Banal na Bibliya, mula sa "Aklat ng Hebreo," "Faith is the assurance of things hoped for, the conviction of things not seen." 10 Nangangahulugan lamang na ang pananampalataya ay ang pagtitiwala na magkakaroon ng katuparan ang anumang inaasam at mayroong paniniwala sa mga bagay na hindi niya nakikita tulad ng paniniwala sa kapangyarihan ni Kristo.

Mayroong tatlong katangian ang pananampalataya: paniniwala (believing) na tumutukoy sa pagkilala sa presensya ng Panginoon katulad ng malalim na pag-unawa na mayroon tayong mga magulang, pangalawa ang paggawa (doing) na nangangahulugang pagsunod o pagsasagawa ng turo ng Panginoon, at pangatlo ang pagtitiwala (trusting) ng lahat sa kamay ng Panginoon. Ito ay nagmumula sa puso ng bawat indibidwal at ito ay lumalago sa pamamagitan ng pagdarasal at pagsamba sa Diyos. ${ }^{11}$

Sa pagkakataong ito, makikita sa mga namimintuho kay Maria ang konsepto nila ng pananampalataya sa Panginoon sa intersesyon ni Maria. Sa kanilang mga liham ng petisyon, makikita sa mga deboto na sila ay nabubulag ng kanilang depinisyon ng paniniwala at pananampalataya sapagkat may mga pagkakataong ang isang debotong humihiling ay lumalampas sa limitasyon niya bilang taong naniniwala at nagtitiwala. Nililinlang niya ang kaniyang sarili sa mga pagkakataong nakaramramdam siya ng matinding depresyon at desperasyon na makamit ang kahilingan.

Matutunghayan sa ibaba ang buod ng mga huwarang liham na naglalaman ng ideyolohiya.

\begin{tabular}{|c|c|c|}
\hline KATEGORYA & $\begin{array}{c}\text { Bilang ng } \\
\text { Liham }\end{array}$ & IDEYOLOHIYA \\
\hline $\begin{array}{c}\text { K1: } \\
\text { Espiritwal na Biyaya }\end{array}$ & D1-D5 & $\begin{array}{l}\text { - } \text { mayroong pag-amin ng pagkakamali } \\
\text { - nakasalalay pa rin sa mga pahiwatig/hudyat sa } \\
\text { pamamagitan ng mga himala ang pagbabago ng } \\
\text { tao } \\
\text { - tanging ang pagtawag lamang niya sa Panginoon } \\
\text { ang makatutulong sa kaniya }\end{array}$ \\
\hline $\begin{array}{c}\text { K2: } \\
\text { Pagbabalik-loob }\end{array}$ & D6-D10 & $\begin{array}{l}\text { - paniniwalang kung hindi maghihimala ang Mahal } \\
\text { na Ina ay hindi na magkakaroon ng pagbabago sa } \\
\text { kaniyang kapatid } \\
\text { - iniuugnay niya ang pagbabago ng kaniyang asawa }\end{array}$ \\
\hline
\end{tabular}

${ }^{10}$ Heb. 11:1 (ESV).

${ }^{11}$ See Catholic Bishop's Conference of the Philippines (CBCP), Catechism for Filipino Catholics (Manila: ECCCE Word \& Life Publications, 2008), 35-36. 


\begin{tabular}{|c|c|c|}
\hline & & $\begin{array}{l}\text { sa pamamagitan ng ibang tao na magsisilbing } \\
\text { instrumento sa pagbabalik-loob sa Diyos } \\
\text { - umaasa lamang sa kilos na gagawin ni Maria } \\
\text { kaugnay sa pagbabago ng asawa at paghinto ng } \\
\text { bisyo nito } \\
\text { - iniaasa sa Mahal na Birhen ang pagbabago ng } \\
\text { kaniyang anak }\end{array}$ \\
\hline $\begin{array}{c}\text { K3: } \\
\text { Kapayapaan sa } \\
\text { Tahanan }\end{array}$ & D11-D15 & $\begin{array}{l}\text { - pag-uutos na mabago ang ugali ng asawa o } \\
\text { hiwalayan nito ang kinakasama } \\
\text { - umaasa na lamang sila sa magiging tugon mula sa } \\
\text { kaniyang pagdarasal batay na rin sa pahayag } \\
\text { nilang "humihingi”, “sana” at "hipuin” para ang } \\
\text { kanilang mga asawang napaibang landas ay } \\
\text { magbalik-loob } \\
\text { - naniniwalang si Mama Mary lamang ang may } \\
\text { kakayahang makapagpabago ng masamang ugali } \\
\text { ng kaniyang manugang }\end{array}$ \\
\hline $\begin{array}{c}\text { K4: } \\
\text { Pagkakasundo }\end{array}$ & D16-D24 & $\begin{array}{l}\text { - sa mga pagkakataong wala nang magagawa, } \\
\text { iniaasa na lamang sa pagkilos ni Maria ang } \\
\text { kanilang hiling } \\
\text { - wala ibang inaasahan upang matupad ang } \\
\text { kanilang kahilingan kundi ang tulong na himala at } \\
\text { panalangin na lamang sa Mahal na Ina } \\
\text { - tinitingnan na walang imposible sa Diyos kaya } \\
\text { lahat ay kaya nitong gawin } \\
\text { - pagsusumamo ng pagkilos ng Mahal na Ina para } \\
\text { sa kaniyang asawa } \\
\text { - pakikipagtawaran sa Panginoon o kay Maria } \\
\text { nobena ay mayroon nang katuparan ang hiling } \\
\text { - pag-asa na maayos ang relasyon sa pamamagitan } \\
\text { ng panalangin }\end{array}$ \\
\hline $\begin{array}{c}\text { K5: } \\
\text { Katuwang sa Buhay }\end{array}$ & D25-D33 & $\begin{array}{l}\text { - } \text { paghingi ng mga senyales/pahiwatig } \\
\text { - sinusukat ang kakayahan ni Kristo na } \\
\text { magdesisyon para sa kaniyang ikabubuti } \\
\text { - umaasa na lamang sa himala } \\
\text { - pag-asa sa ipagkakaloob ni Maria na katuwang sa } \\
\text { buhay sa pamamagitan ng nobena } \\
\text { - labis na pagnanais o despresyon ng deboto } \\
\text { kaugnay sa pagbibigay sa kaniya ng Mahal na Ina } \\
\text { ng makakasama habambuhay }\end{array}$ \\
\hline $\begin{array}{c}\text { K6: } \\
\text { Kalusugan at } \\
\text { Paggaling }\end{array}$ & D34-D49 & $\begin{array}{l}\text { - matinding depresyon ng isang kaanak na } \\
\text { mabigyan o madugtungan pa ang buhay ng taong } \\
\text { kanilang mahal } \\
\text { - pag-asa sa himala o milagro ng pagpapagaling ni } \\
\text { Maria } \\
\text { - pag-asa sa maka-inang pagkalinga ni Maria na }\end{array}$ \\
\hline
\end{tabular}

(c) 2015 Jennifer M. Casabuena http://www.kritike.org/journal/issue 17/casabuena december2015.pdf ISSN 1908-7330 


\begin{tabular}{|c|c|c|}
\hline & & $\begin{array}{l}\text { hindi sila bibiguin } \\
\text { - pagbuo ng pangako sa paniniwalang mas mainam } \\
\text { ito upang matupad ang panalangin } \\
\text { - pag-asa sa bisang dala ng pagnonobena }\end{array}$ \\
\hline $\begin{array}{c}\text { K7: } \\
\text { Kaligtasan sa Sakuna }\end{array}$ & \multicolumn{2}{|c|}{$\begin{array}{l}\text { walang gaanong makikitang mga paglalahad o pagsasalaysay ng } \\
\text { kahilingan ang mga deboto kaugnay sa kategoryang ito }\end{array}$} \\
\hline $\begin{array}{c}\text { K8: } \\
\text { Pagkakaroon ng Anak }\end{array}$ & D50- D53 & $\begin{array}{l}\text { - umaasa sa himala ng pagdadalantao na } \\
\text { ipagkakaloob sa kanila ni Maria } \\
\text { - kinukumpleto ang siyam na nobena para sa Ina } \\
\text { ng Laging Saklolo sapagkat naniniwala sila na sila } \\
\text { ay pagkakalooban ng anak }\end{array}$ \\
\hline $\begin{array}{c}\text { K9: } \\
\text { Tulong Pinansyal }\end{array}$ & D54- D64 & $\begin{array}{l}\text { - pagpapaubaya ng kahilingan kay Maria at pag-asa } \\
\text { na hindi sila bibiguin } \\
\text { - kawalan nila ng pag-asa na lusutan ang kanilang } \\
\text { problema at maniwala na lamang sa tulong at } \\
\text { saklolo ni Maria } \\
\text { - lubusang pag-asa ng deboto sa panalangin } \\
\text { - paniniwalang himala na lamang ni Maria ang } \\
\text { makatutulong sa kaniyang problemang pinansyal } \\
\text { - desperasyon na matugunan ang pangangailangan } \\
\text { - paghahangad sa mabilisang pagtugon sa } \\
\text { panalangin } \\
\text { - pagpapakahulugan sa pagnonobena bilang } \\
\text { katuparan ng mga temporal nilang } \\
\text { pangangailangan } \\
\text { iminikilala nilang maawain si Maria at walang }\end{array}$ \\
\hline $\begin{array}{c}\text { K10: } \\
\text { Tagumpay sa Pag- } \\
\text { aaral }\end{array}$ & D65- D68 & $\begin{array}{l}\text { - pagpapaubaya ng hiling sa pamamagitan ng } \\
\text { himala } \\
\text { - paniniwalang mababago ang marka sa } \\
\text { pamamagitan ng panalangin } \\
\text { - paniniwala sa himala ng pagdarasal kaugnay sa } \\
\text { pagkakaroon ng sipag at talino ng anak } \\
\text { - nakasalalay lamang sa Mahal na Ina ang kaniyang } \\
\text { pagpasa at kaniyang pagtatapos }\end{array}$ \\
\hline $\begin{array}{c}\text { K11: } \\
\text { Pagpasa sa Eksam }\end{array}$ & D69- D73 & $\begin{array}{l}\text { - ang kanilang matinding kagustuhan o pagnanasa } \\
\text { na matamo ang isang bagay ang nag-uudyok sa } \\
\text { kanila upang umasa sa himala ni } \\
\text { Mariapaniniwalang sapagkat si Maria ay } \\
\text { mapagbigay na ina, ipagkakaloob nito ang } \\
\text { anumang nais nila kahit na wala naman silang } \\
\text { gawin }\end{array}$ \\
\hline $\begin{array}{c}\text { K12: } \\
\text { Pagbyahe sa Ibang } \\
\text { Bansa }\end{array}$ & D74- D77 & $\begin{array}{l}\text { - paniniwalang si Maria ay mapaghimalang birhen } \\
\text { ang nagbubunsod sa kanilang upang maniwala }\end{array}$ \\
\hline K13: & D78 - D84 & $\begin{array}{l}\text { - dahil sa deboto sila ng Mahal na Ina ng Laging } \\
\text { Saklolo ay ipagkakaloob ang kanilang nais }\end{array}$ \\
\hline
\end{tabular}

(c) 2015 Jennifer M. Casabuena

http://www.kritike.org/journal/issue 17/casabuena december2015.pdf

ISSN 1908-7330 


\section{MGA LIHAM SA INA NG LAGING SAKLOLO}

\begin{tabular}{|c|c|c|}
\hline $\begin{array}{c}\text { Pagkakaroon ng } \\
\text { Trabaho }\end{array}$ & & $\begin{array}{l}\text { - sa kahinaan ng loob, si Maria na lamang ang pag- } \\
\text { asang makatutulong sa kanila } \\
\text { - may himig ng pag-uutos sa Mahal na Birhen } \\
\text { hinggil sa kanilang nais }\end{array}$ \\
\hline $\begin{array}{l}\text { K14: } \\
\text { Katarungan at } \\
\text { Kapayapaang } \\
\text { Panlipunan }\end{array}$ & D85 & $\begin{array}{l}\text { - paghiling sa kalutasan ng kaso ukol sa demolisyon } \\
\text { dahil walang ibang mahihingan ng tulong kundi si } \\
\text { Maria }\end{array}$ \\
\hline $\begin{array}{c}\text { K15: } \\
\text { Legal na Biyaya }\end{array}$ & D86- D87 & $\begin{array}{l}\text { - paniniwala sa kapangyarihan ni Maria sa } \\
\text { pagkakaloob ng himala hinggil sa pagpapawalang- } \\
\text { sala ng mga nasasakdal sa kaso }\end{array}$ \\
\hline $\begin{array}{c}\text { K16: } \\
\text { Materyal na Biyaya }\end{array}$ & D88- D91 & $\begin{array}{l}\text { - umaasang pagkakalooban ng mga ari-ariang labis- } \\
\text { labis sa pamamagitan ng kanilang pagdarasal pa } \\
\text { rin sa Ina ng Laging Saklolo } \\
\text { - pagnanasang makatakas sa hirap na kanilang } \\
\text { pinagdadaanan }\end{array}$ \\
\hline $\begin{array}{c}\text { K17: } \\
\text { Lahat ng Biyaya }\end{array}$ & D92- D96 & $\begin{array}{l}\text { - tinitingan nila ang debosyon kay Maria bilang } \\
\text { isang "paghiling" o “wishing well” } \\
\text { - pag-asa sa paghiling sa Ina ng Laging Saklolo ng } \\
\text { lahat ng biyayang materyal at di materyal }\end{array}$ \\
\hline
\end{tabular}

Talahanayan 1: Mga nilalaman ng mga

liham na mayroong ideyolohiya

Batay sa mga naging liham ng mga deboto kaugnay sa ideyolohiya o panlilinlang sa/ng mga deboto sa kanilang mga sarili, nakita ang ideyolohiya o pambubulag ayon sa kung paanong humihiling ang mga deboto sa Ina ng Laging Saklolo at kung paano nila tinatanaw na matutupad ang mga kahilingang ito. Ipinakikita sa 410 liham o 27\% ng kabuuang liham na sinuri ang ideyolohiya na nangingibabaw sa mga deboto. Mula sa mga halimbawa ng liham na sinuri sa larangan ng ideyolohiya, marami sa mga deboto ay nabubulag ayon sa sumusunod na mga kadahilanan: a) Ina ng Laging Saklolo ayon na rin sa titulo ng Mahal na Birhen bilang isang ina na palaging handang sumaklolo at tumugon sa mga pangangailangan ng tao; b) desperasyon o matinding pagnanasa ng isang bagay sa panahong wala na silang magawa; c) paniniwala na sa pagtatapos ng nobena sa Ina ng Laging Saklolo ay makakamit nila ang kanilang hangarin sa buhay, at d) pag-asa ng mga deboto sa himala upang matamo ng kanilang minimithi sa buhay.

Ang unang prominenteng ideolohiya ay ang pagtingin o pagtanaw ng mga deboto sa Ina ng Laging Saklolo ayon sa titulo ng Mahal na Birhen bilang isang ina na palaging handang sumaklolo at tumugon sa mga pangangailangan ng tao. Sa pagtingin nila sa ganitong aspekto sa Mahal na Birhen, mayroon silang tendensiya na ipaubaya na lamang sa kanya ang lahat kahit na sa parte nila ay wala naman silang ginagawa. Mayroon silang 
paniniwala na sa pagdarasal sa Mahal na Ina ipagkakaloob nito ang anumang kanilang naisin. Para sa kanila walang imposible kaya Maria at lahat ay kaya nitong gawin.

Pangalawang aspekto ng pambubulag sa mga deboto ay ang kanilang desperasyon o matinding pagnanasa sa isang bagay sa panahong wala na silang magawa. Maaring tumukoy ito sa unang elemento ni Mannheim kaugnay sa ideyolohiya sapagkat nililinlang sila ng kanilang labis na pangangailangan o desperasyon para makita nila kung ano talagang dapat nilang gawin sa sitwasyong kinalalagyan nila. Mayroong mga debotong lumalapit sa Mahal na Ina sa mga panahong wala na silang alam na paraan upang mabigyang solusyon ang kanilang problema o suliraning pinagdaraanan sa buhay pansarili man o pampamilya.

Pangatlo namang aspekto na bumubulag sa mga deboto ay ang kanilang paniniwala na sa pagtatapos o pagsasagawa ng nobena sa Ina ng Laging Saklolo, makakamit nila ang kanilang hangarin sa buhay. May mga debotong malinaw na naghahayag na sa pagtatapos ng kanilang pagnonobena ay inaasahan na nila ang katuparan ng kanilang pangarap.

Pang-apat ay ang pag-asa ng mga deboto sa himala na matamo ng kanilang minimithi sa buhay. Sa halip na gumawa sila ng paraan, ang kanilang matinding paghahangad na makamit ang mga hinihiling nila ay idinadaan nila sa paniniwala na pagkakalooban sila ni Maria ng himala. Nabubulagan sila sa ideya na sa kanilang pagtawag at paghingi kay Maria, kahit na ito ay imposible, naniniwala silang ito ay magaganap sapagkat walang imposible kay Maria dahil mayroong himala.

Batay sa pagsusuring ginawa sa mga liham sa larangan ng ideyolohiya, natuklasan na ang pangunahing elementong nangingibabaw sa mga deboto ay ang elementong nag-uudyok sa isang taong linlangin niya ang kaniyang sarili hinggil sa tunay na kaayusan ng reyalidad. Madalas ay nililinlang ng isang deboto ang kaniyang sarili sa kaniyang paniniwala na maipagkakaloob sa kaniya ang anumang kaniyang nais sa pamamagitan ng matiyaga at matinding pagtawag kay Maria.

Napatunayan din sa pag-aaral na ito na nangingibabaw ang ideyolohiya sa mga kahilingan ng mga deboto ukol sa pagkakasundo, paghiling ng mga kababaihan ng katuwang sa buhay, kalusugan at paggaling, at ang pagkakaloob ng pinansyal na tulong na karamihan ay humihingi ng himala ng pagkapanalo ng jackpot sa lotto.

Mula sa mga halimbawang ipinakita sa pagsusuring ito ng ideyolohiya, makikita na tinitingnan ng mga deboto ang pagdarasal nila ng petisyon bilang isang mahika na magbibigay sa kanila ng kanilang gusto. Sila ay nabubulag sa ideya na sa pamamagitan ng kanilang masidhing pagdarasal sa Mahal na Ina, magkakaroon ito ng awa upang ibigay sa kanila ang kahilingang minimithi. Madalas ay hindi nakikita ng deboto ang tunay na

(c) 2015 Jennifer M. Casabuena

http://www.kritike.org/journal/issue 17/casabuena december2015.pdf

ISSN 1908-7330

(cc) BY-NC-ND 
estado ng reyalidad na kaniyang kinalalagyan at madalas ay nabubulag sa paniniwala na magkakaroon ng pagbabago dahil sa siya ay nagdasal. Nakakalimutan nila ang tunay na esensya ng pagdarasal na pagsusuko ng panalangin kay Kristo at pagpapaubaya na lamang sa Kanya kung ano ang nararapat.

\section{Antas at Hugis ng Utopia sa mga Liham}

Ang utopia sa pag-aaral na ito ay tumutukoy sa mga pangarap, hangarin, o mithiin ng isang tao na nagkakaroon ng katuparan tungo sa pagtatamo ng kaayusang panlipunan.

Ayon kay Bloch malaki ang ginagampanan ng pangarap sa pagimpluwensya kung paano natin titingnan ang mundo sa pagpuuno ng tao ng kaniyang buhay ng mga paniniwala, ilusyon at pangarap, at delusyon. Ang ugat ng mga hangaring pantaong ito ay ang kasalukuyang kalagayan ng tao na nababalot ng iba't ibang mga pangangailangan ng tao tungo sa pagkakamit ng kaginhawaan. Ang mga pangarap ding ito ay ekspresyon ng pangangailangan at pangarap ng tao sa kabila ng mga pagkontrol ng lipunan.

Sa kabila ng mahirap na pamumuhay ng marami sa mga Pilipino, ang kanilang pag-asa na mabago ito ay higit pa sa pagtupad ng isang pangarap. Ang pag-asang ito ang siyang nagpapakilos sa kanila tungo sa magandang hinaharap. Ang utopiang ito ay bisyon ng isang bagong lipunan na nagdadala ng pag-asa at direksyon sa mga taong dukha sa lahat ng kanilang mga paghihirap sa buhay. ${ }^{12}$

Dahil sa mga pangarap na ito, nagkakaroon ng motibasyon ang tao upang magsikap, upang kumilos. Naniniwala si Bloch na malaki ang dulot na pagbabago ng mga pangarap at hangarin ng tao kung ito ay maisasakatuparan lamang. Ang pag-asang nabubuo sa tao na magaganap ang kanilang hangarin ang tinatawag na utopia. ${ }^{13}$ Ang utopia na ito na tinutukoy ni Aguas ang nagbibigay pag-asa sa mga tao na makawala sa kasalukuyang estado ng buhay mayroon sila tungo sa pagkakamit ng isang makatarungang lipunan. Ang pag-asa na nagbibigay ng utopia sa mga tao ay hindi pasibo. Sila ay hindi lamang basta umuupo na lamang at naghihintay sa pagkilos ng Panginoon para mabigyang solusyon ang anumang problemang kanilang pinagdaraanan. Ang kanilang pananampalataya ang humihimok sa kanilang kumilos at makita ang isang lipunang mas malaya at mas may pagkakapantay-pantay.

\footnotetext{
12 See Raymond B. Aguas, Relating Faith and Political Action: Utopia in the Theology of Gustavo Gutierrez (Unpublished Ph.D. Dissertation, Indiana: University of Notre Dame, 2007), 7273.

${ }^{13} \mathrm{Ibid} ., 73$.

(c) 2015 Jennifer M. Casabuena http://www.kritike.org/journal/issue 17/casabuena december2015.pdf ISSN 1908-7330

(c) BY-NC-ND
} 
Matutunghayan sa ibaba ang sipi ng mga liham ng mga deboto na kakikitaan ng utopia sa kanilang mga kahilingan at pasasalamat.

\begin{tabular}{|c|c|c|c|}
\hline \multirow{2}{*}{ KATEGORYA } & \multirow{2}{*}{$\begin{array}{l}\text { Bilang ng } \\
\text { liham }\end{array}$} & \multicolumn{2}{|c|}{ UTOPIA } \\
\hline & & KONKRETO & ABSTRAK \\
\hline $\begin{array}{c}\text { K1: } \\
\text { Espiritwal na Biyaya }\end{array}$ & D97 - D102 & $\begin{array}{l}\text { - lahat sila ay } \\
\text { nagkakaroon ng pagkilos } \\
\text { tungo sa pagtatamo ng } \\
\text { kapatawaran } \\
\text { - mayroong paghahangad } \\
\text { tungo sa pagbabago } \\
\text { - pagtalikod sa mga } \\
\text { maling gawain }\end{array}$ & \\
\hline $\begin{array}{c}\text { K2: } \\
\text { Pagbabalik-loob }\end{array}$ & D103- D106 & $\begin{array}{l}\text { - mayroong paghahangad } \\
\text { na mabago ang maling } \\
\text { gawain } \\
\text { - sa kaniyang } \\
\text { pananampalataya } \\
\text { nagkaroon siya ng } \\
\text { positibong pagtingin sa } \\
\text { buhay at nagawa niyang } \\
\text { iligtas ang kaniyang } \\
\text { sarili sa paggawa ng } \\
\text { masama }\end{array}$ & \\
\hline $\begin{array}{c}\text { K3: } \\
\text { Kapayapaan sa } \\
\text { Tahanan }\end{array}$ & D107-D112 & $\begin{array}{l}\text { - gumagawa ng paraan } \\
\text { upang maisaayos ang } \\
\text { kanilang pagsasama } \\
\text { tulad ng pakikipag-usap, } \\
\text { pagsuyo sa kanilang } \\
\text { asawa at hindi pagsuko } \\
\text { sa mga ito }\end{array}$ & $\begin{array}{l}\text { - pagdulog sa Ina ng } \\
\text { Laging Saklolo at pag- } \\
\text { asa nila sa himala } \\
\text { - nagdidikta sa Ina ng } \\
\text { Laging Saklolo upang } \\
\text { gumawa ng pagkilos } \\
\text { para sa kanilang } \\
\text { hangarin magkaayos } \\
\text { silang mag-asawa }\end{array}$ \\
\hline $\begin{array}{c}\text { K4: } \\
\text { Pagkakasundo }\end{array}$ & D113- D119 & $\begin{array}{l}\text { - may mga ginagawa } \\
\text { upang makahingi ng } \\
\text { tawad sa kaniyang asawa } \\
\text { at muling maayos ang } \\
\text { kanilang pagsasama } \\
\text { - paghahangad ng deboto } \\
\text { na maging daan tungo } \\
\text { sa pagkakaayos ng mag- } \\
\text { ama }\end{array}$ & $\begin{array}{l}\text { - pag-asa na lamang sa } \\
\text { panalangin para sa } \\
\text { pagkakasundo ng mag- } \\
\text { asawa } \\
\text { - pag-asa sa tulong ng } \\
\text { Mahal na Ina sa } \\
\text { pagkakasunod ng } \\
\text { miyembro ng pamilya at } \\
\text { ng pinagkakautangan } \\
\end{array}$ \\
\hline $\begin{array}{c}\text { K5: } \\
\text { Katuwang sa Buhay }\end{array}$ & D120- D124 & $\begin{array}{l}\text { - pangangalaga sa } \\
\text { relasyon } \\
\text { - paghingi ng tulong na }\end{array}$ & $\begin{array}{l}\text { - nakasalalay lamang sa } \\
\text { pagdarasal at pagkilos } \\
\text { ng Ina ng Laging Saklolo }\end{array}$ \\
\hline
\end{tabular}




\begin{tabular}{|c|c|c|c|}
\hline & & $\begin{array}{l}\text { makilala na ang lalaking } \\
\text { pangarap sa buhay } \\
\text { - hindi pagsuko sa } \\
\text { pagmamahal sa kabila ng } \\
\text { lahat ng pinagdaanan sa } \\
\text { buhay pag-ibig }\end{array}$ & \\
\hline $\begin{array}{c}\text { K6: } \\
\text { Kalusugan at } \\
\text { Paggaling }\end{array}$ & D125- D139 & $\begin{array}{l}\text { - ginagawa ring paraan sa } \\
\text { kaniyang sarili upang } \\
\text { matupad ang kaniyang } \\
\text { hangarin sa buhay tulad } \\
\text { ng pagpapagamot }\end{array}$ & $\begin{array}{l}\text { - pag-asam sa isang } \\
\text { milagro na magmumula } \\
\text { kay Maria }\end{array}$ \\
\hline $\begin{array}{c}\text { K7: } \\
\text { Kaligtasan sa } \\
\text { sakuna }\end{array}$ & \multicolumn{3}{|c|}{ walang nakitang huwarang liham } \\
\hline $\begin{array}{c}\text { K8: } \\
\text { Pagkakaroon ng } \\
\text { Anak }\end{array}$ & D140- D147 & $\begin{array}{l}\text { - maaring magkaroon ng } \\
\text { anak lalo na kung } \\
\text { walang karamdaman } \\
\text { - nagpapatingin rin siya sa } \\
\text { doktor upang maging } \\
\text { katotohanan ang } \\
\text { kaniyang pinapangarap } \\
\text { - mayroong medikasyong } \\
\text { pinagdadaanan at } \\
\text { gagawin ang lahat tulad } \\
\text { ng in vitro fertilization } \\
\text { para sa pagkakaroon ng } \\
\text { anak }\end{array}$ & $\begin{array}{l}\text { - hiling na huwag makuha } \\
\text { ng anak niya ang sakit na } \\
\text { tumama sa kaniya }\end{array}$ \\
\hline \multirow[t]{2}{*}{$\begin{array}{c}\text { K9: } \\
\text { Tulong Pinansyal }\end{array}$} & D148-D153 & $\begin{array}{l}\text { - mayroong paghahangad } \\
\text { na makabayad sa utang } \\
\text { at iba pang bayarin } \\
\text { - mayroong ginagawang } \\
\text { paraan at ang pagtawag } \\
\text { kay Maria ay paghingi } \\
\text { lamang ng gabay kasama } \\
\text { ng pagkilos }\end{array}$ & \\
\hline & D154- 158 & & $\begin{array}{l}\text { - pag-asa sa tulong ni } \\
\text { Maria na ibibigay sa } \\
\text { kanila sa pamamagitan } \\
\text { ng pagtama sa lotto } \\
\text { - lubusang pag-asa } \\
\text { lamang sa } \\
\text { kapangyarihan ni Maria } \\
\text { bilang ina }\end{array}$ \\
\hline $\begin{array}{c}\text { K10: } \\
\text { Tagumpay sa Pag- } \\
\text { aaral }\end{array}$ & D159- D163 & $\begin{array}{l}\text { - kumikilos patungo sa } \\
\text { pagtatamo ng pangarap } \\
\text { na makapag-aral o } \\
\text { makapagtapos ng pag- } \\
\end{array}$ & \\
\hline
\end{tabular}

(C) 2015 Jennifer M. Casabuena http://www.kritike.org/journal/issue 17/casabuena december2015.pdf ISSN 1908-7330 


\begin{tabular}{|c|c|c|c|}
\hline & & aaral & \\
\hline \multirow[t]{2}{*}{$\begin{array}{c}\text { K11: } \\
\text { Pagpasa sa Eksam }\end{array}$} & D164- D176 & $\begin{array}{l}\text { - hindi pagsuko at } \\
\text { pagsusumikap upang } \\
\text { makapasa sa eksam } \\
\text { - naniniwala rin siya sa } \\
\text { kapangyarihan ng } \\
\text { panalangin kasama ang } \\
\text { gawa } \\
\text { - pinagsisikapan ang } \\
\text { pagrerebyu } \\
\end{array}$ & \\
\hline & D177-D178 & & $\begin{array}{l}\text { - umaasa na siya ay } \\
\text { papasa sa eksam } \\
\text { sapagkat ayon sa kanya } \\
\text { ay marami nang } \\
\text { naipagkaloob sa } \\
\text { kaniyang ang Mahal na } \\
\text { Ina }\end{array}$ \\
\hline $\begin{array}{c}\text { K12: } \\
\text { Pagbyahe sa Ibang } \\
\text { Bansa }\end{array}$ & D179- D186 & $\begin{array}{l}\text { - nagsusumikap na } \\
\text { maayos at } \\
\text { makapagsumite ng mga } \\
\text { papeles na kailangan } \\
\text { - di pagsuko sa prosesong } \\
\text { pinagdaraanan } \\
\text { - may lakas ng loob na } \\
\text { harapin ang pagsubok na } \\
\text { panayam } \\
\text { - pagsusuko ng kahilingan } \\
\text { kay Maria bagamat } \\
\text { mayroong ginagawang } \\
\text { paraan sa pag-aaplay } \\
\text { abroad }\end{array}$ & \\
\hline $\begin{array}{c}\text { K13: } \\
\text { Pagkakaroon ng } \\
\text { Trabaho }\end{array}$ & D187- D195 & $\begin{array}{l}\text { - humihingi ng tulong } \\
\text { kaugnay sa kanilang } \\
\text { pag-aaplay } \\
\text { - patnubay at gabay ang } \\
\text { kanilang hinihingi } \\
\text { habang kasalukuyang } \\
\text { nilang tinatahak ang } \\
\text { kanilang pag-aaplay } \\
\text { - pursigido sa paghahanap } \\
\text { ng trabaho } \\
\text { - tagumpay sa } \\
\text { pangangasiwa ng } \\
\text { negosyoagpapaubaya sa } \\
\text { Diyos ng kahihinatnan } \\
\text { ng pag-aaplay }\end{array}$ & \\
\hline
\end{tabular}




\begin{tabular}{|c|c|c|c|}
\hline & D196- D200 & & $\begin{array}{l}\text { - umaasa sa tugon at } \\
\text { pagtulong ng Ina ng } \\
\text { Laging Saklolo sa } \\
\text { pamamagitan ng } \\
\text { panalangin }\end{array}$ \\
\hline $\begin{array}{l}\text { K14: } \\
\text { Katarungan at } \\
\text { Kapayapaang } \\
\text { Panlipunan } \\
\end{array}$ & \multicolumn{3}{|c|}{ walang nakitang huwarang liham } \\
\hline $\begin{array}{c}\text { K15: } \\
\text { Legal na Biyaya }\end{array}$ & D201- D206 & $\begin{array}{l}\text { - maaring magkaroon ng } \\
\text { kalayaan sa kaso kung } \\
\text { mapapatunayan nila na } \\
\text { wala talaga silang } \\
\text { kasalanan } \\
\end{array}$ & $\begin{array}{l}\text { - kung sa kanilang } \\
\text { pagdarasal, wala silang } \\
\text { ibang inaasahan kundi } \\
\text { ang kilos ng Ina ng } \\
\text { Laging Saklolo } \\
\end{array}$ \\
\hline $\begin{array}{c}\text { K16: } \\
\text { Materyal na Biyaya }\end{array}$ & D207-D208 & $\begin{array}{l}\text { - naghahangad na } \\
\text { makabili ng bahay at } \\
\text { lupa mula sa } \\
\text { pagtratrabaho }\end{array}$ & \\
\hline $\begin{array}{c}\text { K17: } \\
\text { Lahat ng Biyaya }\end{array}$ & \multicolumn{3}{|c|}{ walang nakitang huwarang liham } \\
\hline $\begin{array}{c}\text { K18: } \\
\text { Pasasalamat }\end{array}$ & D209- 215 & $\begin{array}{l}\text { - nagawa niyang mairaos } \\
\text { ang kaniyang pag-aaral } \\
\text { sa graduate school } \\
\text { - nagawa ng anak niya na } \\
\text { makakuha ng iskolarsyip } \\
\text { sa pinapangarap nitong } \\
\text { unibersidad } \\
\text { - naglahad ng kaniyang } \\
\text { pinagdaanan bilang ina } \\
\text { sa pagpapaaral sa } \\
\text { kaniyang anak } \\
\text { - nagpapasalamat na } \\
\text { nakapasa siya sa } \\
\text { eksaminasyon niya na } \\
\text { nabigay sa kanya ng } \\
\text { pinakamataas na } \\
\text { karangalang na maging } \\
\text { isang medical } \\
\text { technologist } \\
\text { - nagkaroon ng katuparan } \\
\text { ang kaniyang panalangin } \\
\text { na maaparubahan ang } \\
\text { kanyang aplikasyon } \\
\text { patungo sa Canada } \\
\text { nagpapasalamat } \\
\text { sapagkat siya ay } \\
\text { gumaling matapos }\end{array}$ & \\
\hline
\end{tabular}




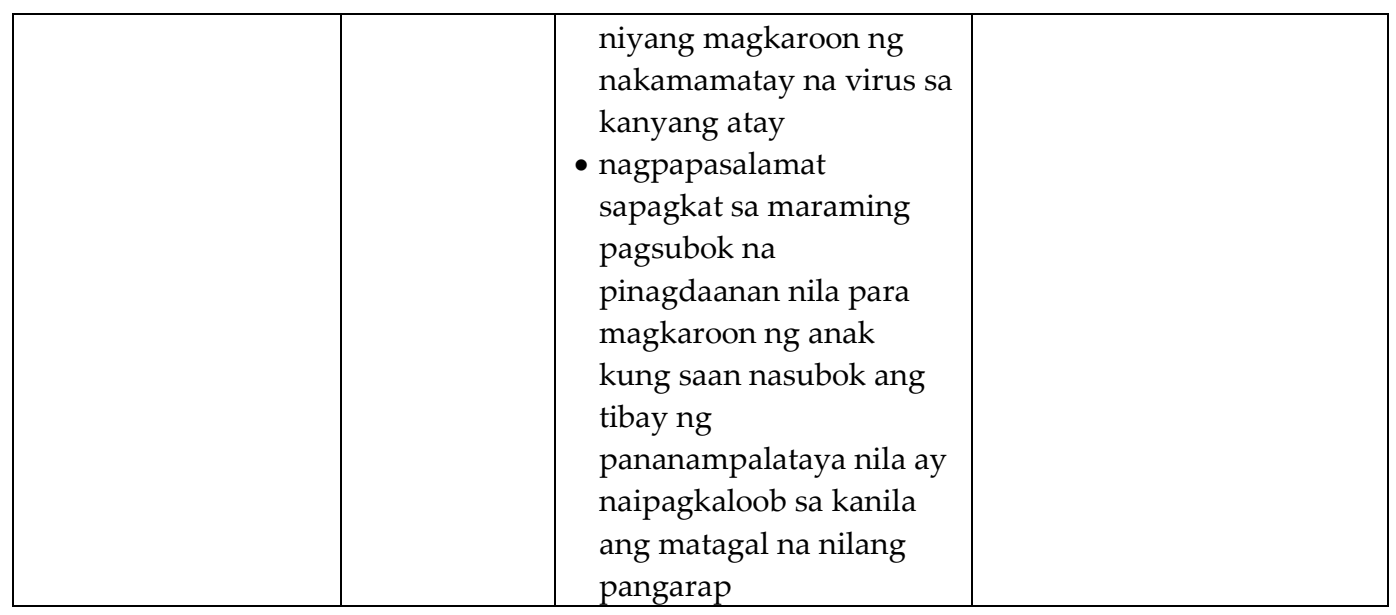

Talahanayan 2: Mga nilalamang utopia ng mga liham na sinuri

Sa larangan naman ng utopia, makikita ang pangingibabaw ng konkretong utopia sa mga liham sapagkat makikita ang pagkilos ng mga deboto kasama ng kanilang pagdarasal sa pagtatamo ng kanilang mga kahilingan. Ayon rin sa naging resulta ng panayam sa mga deboto, higit na nangibabaw ang utopia sa kanilang mga kahilingan sapagkat sa kanilang paghiling o pagdarasal sa Mahal na Ina, hindi sila umaasa na lamang sa panalangin. Sila ay mayroong kamalayan at kaalaman sa kanilang sarili na sa bawat pagdarasal nila sa Panginoon sa pamamagitan ni Maria, mahalaga ang kanilang paggawa upang maging positibo ang tugong makuha.

Sa mga liham na sinuri, nangingibabaw ang mga konkretong utopia o iyong mga kahilingang mayroong posibilidad na magkaroon ng katuparan sapagkat kakikitaan ng pagkilos ang mga deboto tungo sa pagtatamo ng kanilang mga hangarin tulad ng mga kahilingan sa: espiritwal na biyaya, pagbabalik-loob, pagkakaroon (o pagsasama ng) katuwang sa buhay, kalusugan at paggaling sa hindi malalang karamdaman, pagkakaroon ng anak, tulong pinansyal (sa pagnanasang makabayad ng utang), pag-aaral, pagpasa sa eksam, pagbyahe sa ibang bansa, at pagkakaroon ng trabaho. Ang mga debotong humihiling ng tulong sa Mahal na Ina sa mga larangang ito ay hindi lubusang umaasa sa himala. Marami sa kanila ay isinusuko ang kanilang kahilingan sa Panginoon sa tulong ni Maria at ipinauubaya na lamang kung ano ang mangyayari sa kanilang pagsisikap na ginagawa.

Ang mga liham ng pasasalamat ay nagpapakita rin ng konkretong utopia sapagkat patunay ito ng katuparan ng kanilang mga kahilingan. Makikita sa kanilang paghiling na mayroon silang ginagawang kilos para magkaroon ng katuparan ng kanilang mga kahilingan. Hindi sila lubusang umaasa na lamang sa panalangin at naghihintay sa mga senyales o pahiwatig bago gawin ang pagkilos. Makikita sa mga deboto na sabay nilang ginagawa

(C) 2015 Jennifer M. Casabuena http://www.kritike.org/journal/issue 17/casabuena december2015.pdf ISSN 1908-7330 
ang pagdarasal gayundin ang kanilang paghingi ng tulong at gabay ni Maria upang patnubayan silang matupad ang kanilang hinihiling.

Samantala nakita naman ang pangingibabaw ng abstrak na utopia sa mga kahilingan sa katuwang sa buhay, pagkakasundo, pagbabalik-loob, kapayapaan sa tahanan, pinansyal na tulong, kalusugan, at legal na biyaya. Sa mga aspektong ito, bagamat mayroong nakitang konkretong utopia, mas nangibabaw ang pagiging abstrak sapagkat mayroon sa kanilang nagpahayag ng pag-asa na rin nila sa himala kaugnay sa kagalingan ng mahal sa buhay, pagkakaroon ng maraming salapi, at pagpapawalang-sala sa mga kasong kinasangkutan.

Higit na nangingibabaw sa mga liham ng mga deboto ang konkretong utopia sapagkat makikita sa mga deboto na kasabay ng kanilang pagdarasal, sila ay mayroong ginagawa kaugnay ng kanilang mga kahilingan upang magkaroon ng posibilidad na ito ay magkaroon ng katuparan. Marami sa mga pahayag ng mga debotong lumiham ay hindi lamang umaasa sa panalangin sapagkat malinaw sa kanilang kamalayan na kailangan din nilang kumilos upang matupad ang kanilang hinihiling. Ito ay pagtutulungan sa pagitan nila at ni Kristo, kaya nga ang pilosopiyang "Nasa tao ang gawa, nasa Diyos ang awa" ang pinaniniwalaan ng maraming debotong Pilipino.

Sa kabuuan ng naging pagsusuri ng mananaliksik sa mga liham ng mga deboto sa bawat kategorya, lumalabas na ang nangingibabaw na elemento sa mga liham ng mga deboto ay ang utopia sapagkat makikita sa kanilang mga naratibo na bilang mga taong nagdarasal at humihingi ng tulong sa Panginoon, hindi nila lubusang iniaasa sa Panginoon o kay Maria ang kanilang mga hinihiling. Bagkus, ipinauubaya nila sa Panginoon ang kanilang mga kahilingan kasabay ng kanilang pagkilos tungo sa pagtatamo ng kanilang mga idinudulog kay Maria. Bagamat may kamalayan sila sa banal na kapangyarihan ng Panginoon, hindi nila minamanipula ang Panginoon o si Maria tungo sa pagkakamit ng kanilang personal na hangarin sa buhay.

\section{Implikasyon ng Ideyolohiya/ Utopiang Nakapaloob sa mga Liham sa Usapin ng Pagbabagong-loob at Pagbabago ng Lipunan}

Kaugnay naman ng implikasyon ng mga liham sa larangan ng ideyolohiya, maaring patuloy na malinang sa mga deboto ang sumusunod dahil sa kanilang maling pagtingin o pagtanaw sa kanilang debosyon kay Maria. Ang mga ito ay a) lubusang umasa na lamang sa kakakayahan ng Mahal na Ina na mamagitan para sa kanilang kahilingan, b) tingnan ang kanilang pananampalataya bilang pakikipagtawaran sa Panginoon o kay Maria, c) tingnan ang pagdarasal o paghiling bilang paghingi ng kanilang

(c) 2015 Jennifer M. Casabuena

http://www.kritike.org/journal/issue 17/casabuena december2015.pdf

ISSN 1908-7330

(c) BY-NC-ND 
mga personal na pangangailangan, d) maniwala o umasa na lamang sa himala o maging palaasa, at e) magkaroon ng mababaw na pagtingin sa debosyon.

Una, makikita sa mga deboto ang lubos na pag-asa sa pagkilos ng Mahal na Ina sa pagkakaloob ng kanilang mga kahilingan. Nagkakaroon ng pagkakataon ang mga tao na lumapit sa kanilang pananampalataya at magtiwala na magkakaroon ng pagbabago sa kanilang mga matinding inaasam at pinapangarap sa buhay. Mayroong aspekto ng pambubulag sa mga deboto sapagkat iniaasa na lamang nila sa pagkilos ng Mahal na Ina ang kanilang mga panalangin.

Pangalawa, pinaniniwalaan nila ang kanilang pananampalataya bilang pakikipagtawaran sa Panginoon o kay Maria. Sapagkat ang pangalan ni Maria ay Ina ng Laging Saklolo, hindi nawawala sa kanila ang pagtingin na anumang hiling nila, mayroong posibilidad na matupad lalo na kung sasamahan pa nila ito ng pangako na may mga pagkakataong hindi na natutupad kapag naipagkaloob na ang kanilang hinihiling.

Pangatlo, tinitingnan ang pagdarasal o paghiling bilang paghingi ng kanilang mga personal na pangangailangan. Mas nangingibabaw sa mga tao ang paghiling at pagtitiwala na makakamit nila ang kaginhawaan, seguridad, satispaksyon, at kasiyahan sa pamamagitan ng paghingi ng tulong kay Maria. Tinitingnan nila ang pagdarasal nila sa Panginoon bilang paghingi at pagkakaloob ngunit hindi pagpupuri at pagpapaubaya sa banal Niyang kapangyarihan. Ayaw ng mga debotong tumanggap ng kabiguan sapagkat para sa kanila, palagi silang pagbibigyan anuman ang kanilang hinihiling sapagkat Mahal sila ni Maria.

Pang-apat, ang kanilang pagdarasal ay iniuugnay na lamang nila sa paghingi ng himala sapagkat ang pagkumpleto ng kanilang nobena o kahit ang kanilang pagdarasal ay magdudulot ng sagot sa kanilang hinahangad. Ang kanilang pagnonobena sa Mahal na Birhen ay hindi isang pagdarasal kundi katumbas ng pagkakaloob ng isang hangarin sa buhay. At panghuli, nagiging mababaw ang pananampalataya ng mga deboto resulta ng mababaw na paraan ng pagtingin nila sa kanilang debosyon. Ang tunay na debosyon ay pagsusuko ng sarili sa Panginoon at pagpapaubaya kung ano ang nararapat. Sa ginagawa ng tao, tinitingnan nila ang kanilang debosyon sa mga santo at santa sa pamamagitan ng paghiling at pag-asa na maipagkakaloob ang kanilang mga kahilingan.

Sa usapin naman ukol sa utopia, nakita naman ang mga sumusunod bilang maaring maging epekto ng utopiang nakapaloob sa mga liham: a) paglalim ng pananampalataya, b) pagbabago ng pag-uugali, c) pagtitiwala sa Panginoon, at d) pagpapakita ng tunay na debosyon. Sa mga liham higit na nangingibabaw ang pagbabagong-loob ng indibidwal sapagkat madalas ang kanilang paghiling ay personal na mga pangangailangan. Kaakibat ng mga 


\section{MGA LIHAM SA INA NG LAGING SAKLOLO}

personal na paghiling na ito ang kanilang pagbabago sapagkat natututo silang sumunod at umayon sa kung ano ang niloloob ng Panginoon at upang mas maging karapat-dapat sila sa kanilang mga hinihiling.

Una, makikita ang paglalim ng kanilang pananampalataya sa Panginoon sa pamamagitan ni Maria. Sapagkat ang tao ay naniniwala sa kapangyarihan ng panalangin bilang siyang tulay patungo sa pakikipagugnayan kay Kristo, nagbubunsod ito ng isang makapangyarihang espiritwal na ugnayan sa pagitan ni Kristo at ng tao.

Pangalawa, pagbabago ng sarili ang maidudulot sa tao ng kanilang mga kahilingan sapagkat dahil sa kanilang pananampalataya, lalo na sa pagkakataong nagkakaroon ng katuparan ang kanilang mga kahilingan, nagagawa ng taong magbago tungo sa ikabubuti niya bilang tao at bilang sumasampalataya sa Panginoon. Nagkakaroon ng reyalisasyon ang tao na ang kapangyarihan ng Diyos at ang makainang pagtulong sa kanila ni Maria ay isang patunay ng pagbabantay sa kanila. Makikita sa mga debotong humihiling sa Ina ng Laging Saklolo ang pagtanaw nila ng utang na loob sa kabutihan nito sa kanila.

Pangatlo, nabubuo ang buong pagtitiwala sa Panginoon ng mga deboto sapagkat sa kanilang pagdarasal umaasa silang pagkakalooban sila sa kanilang kahilingan. Bagamat sila ay kumikilos o gumagawa para sa katuparan ng panalanging ito, hindi nawawala sa mga deboto ang kanilang pagtataas ng kanilang mga sarili sa Panginoon upang maipagkaloob sa kanila kung ano ang nararapat. May mga pagkakataong ang mga deboto ay naniniwalang ipagkakaloob sa kanila ang kanilang kahilingan sa tamang panahon.

Panghuli, nagpapakita ng tunay na debosyon ang mga liham ng nakararami sa mga deboto sapagkat tumutukoy ito sa panloob na gawi ng tao tulad ng pagsuko, dedikasyon, at ang kahandaan na gawin ang lahat para sa Panginoon. Sa pagkakataong ito, magiging tunay ang debosyon ng isang tao sapagkat bukod sa kanilang pagdarasal, naroroon ang tunay na pagsusuko ng kanilang mga kahilingan sa kalooban ng Diyos.

Mula sa mga natuklasang implikasyon ng ideyolohiya at utopiang nakapaloob sa mga liham, masasabing sa mga kahilingan ng mga deboto na maaaring magkaroon ng positibo at negatibong epekto sa isang tao o deboto ang labis niyang pagpapaubaya at pag-asa sa pamimintuho kay Maria. Batay sa mga halimbawang liham na nakalap, higit na nangingibabaw ang positibong epekto nito sa mga deboto tungo sa kanilang pagbabago upang maging isang mabuting Kristyano at mamamayan na mayroong paniniwala kay Kristo. Sa pagdanas ng mga deboto ng ginhawa ng kalooban sa kanilang pakikipag-ugnayan kay Maria at sa katuparan ng kanilang mga pangarap, nagkakaroon sila ng pagtanaw ng utang na loob sa Panginoon na

(C) 2015 Jennifer M. Casabuena

http://www.kritike.org/journal/issue 17/casabuena december2015.pdf

ISSN 1908-7330

(cc) BY-NC-ND 
magbubunsod ng kanilang pagbabago na maaring personal na magbubunsod sa maayos nilang pakikipag-ugnayan sa kanilang kapwa.

\section{Konklusyon}

Mula sa ginawang pag-aaral, natuklasan na sa pagkapit ng mga deboto sa Ina ng Laging Saklolo sa panahon ng kanilang pangangailangan, malaki ang papel na ginagampanan ni Maria sa buhay ng maraming mga Pilipino. Sa pamamagitan ng kanilang mga liham, natuklasan kung paanong tinitingnan ng mga deboto ang kanilang debosyon at pamimintuho sa Ina ng Laging Saklolo.

Matapos na maisagawa ang pag-aaral, nabuo sa mananaliksik ang maka-Pilipinong pamamaraan ng debosyon kay Maria. Ang debosyon ng mga Pilipinong deboto sa Ina ng Laging Saklolo ay nagsisimula sa kanilang pagtanaw kay Maria bilang kanilang Inang malalapitan nila sa kanilang pangangailangan. Si Maria ay itinuturing nila bilang "hindi ibang tao" kaya nagagawa nilang maging totoo sa kanya. Si Maria, bilang ina na palaging handang tumugon sa kanilang hinain, ang nagsisilbi nilang pag-asa sa buhay tungo sa pagkakamit ng kaginhawaan at kapanatagan ng kalooban. Bilang inang kumakalinga sa kaniyang anak, si Maria ang nagsisilbi nilang takbuhan bilang taong hindi nawawalan ng mga suliranin at pasanin sa buhay.

Mayroong makahulugang tunog sa mga tao ang pangalan niyang Ina ng laging Saklolo-dalawang salitang mayroong malalim na kahulugan sa mga Pilipinong mananampalataya. Sa kanilang pakikipagtunguhan kay Maria, natuklasan ng mananaliksik sa pag-aaral na ito ang proseso ng pagpapalalim ng kanilang debosyon: pagsubok, padalaw-dalaw, pakikilahok, pakikipagpalagayang-loob, at pakikiisa.

Natuklasan din sa pag-aaral na ang pangunahing gawain ng mga deboto na tanda ng kanilang debosyon ay ang mga sumusunod: pagnonobena, pagtanod kapag araw ng Martes, paglalakad nang paluhod, pagsalat sa imahen ng Ina ng Laging Saklolo, pagdarasal ng Santo Rosaryo, boluntaryong paglilingkod sa Dambana ng Ina ng Laging Saklolo, at paghuhulog ng liham sa dambana.

Sa pagsusuring ginawa naman sa mga liham, natuklasan na ang mga pangunahing kahilingan ng mga deboto na kakikitan ng ideyolohiya ay pawang tumatalakay ukol sa paggaling mula sa karamdaman, tulong pinansyal, pagkakaroon ng katuwang sa buhay, at pagkakasundo. Makikita naman ang pangingibabaw ng konkretong utopia sa mga liham kaugnay ng espiritwal na biyaya, pagbabalik-loob, kalusugan at paggaling sa hindi malalang karamdaman, pagkakaroon ng anak, tulong pinansyal sa larangan ng pagnanasang makabayad ng utang, pag-aaral, pagpasa sa eksam, 
pagbyahe sa ibang bansa, at pagkakaroon ng trabaho. Sa dalawang elementong ito, higit na nangingibabaw sa mga liham ang utopia sapagkat kakikitaan ang karamihan sa mga deboto ng kanilang pagkilos at paggawa tungo sa pagtatamo ng kanilang hinahangad. Ang kanilang pagdarasal kay Hesus sa pamamagitan ni Maria ay paghingi lamang ng patnubay at gabay tungo sa katuparan ng kanilang hinihiling. Naniniwala ang marami sa mga debotong nagdarasal na ang katuparan ng anumang hinihiling ng tao ay nakasalalay pa rin sa kaniyang pagkilos.

Ang implikasyong nakapaloob naman sa mga liham na nagtataglay ng ideyolohiya ay nagbubunsod sa deboto upang lubusang umasa na lamang sa kakayahan ng Mahal na Ina na mamagitan para sa kanilang kahilingan, tingnan ang kanilang pananampalataya bilang pakikipagtawaran sa Panginoon o kay Maria, tingnan ang pagdarasal o paghiling bilang paghingi ng kanilang mga personal na pangangailangan, maniwala o umasa na lamang sa himala o maging palaasa at magkaroon ng mababaw na pagtingin sa debosyon. Samantala sa utopia naman, nagagawa nitong mapalalim ang pananampalataya ng mga deboto, mabago ang anumang masasama o di kanais-nais na pag-uugali ng isang tao, magkaroon ng pagtitiwala sa kapangyarihan ng Panginoon, at magpakita ng tunay na debosyon sa Ina ng Laging Saklolo.

Sa paglapit ng mga deboto sa Ina ng Laging Saklolo, higit na nangingibabaw ang positibong epekto sa mga deboto sapagkat sa pamamagitan ng kanilang malalim na pagtingin kay Maria bilang isang ina, binibigyang pagpapahalaga nila ang pagkakaroon ng katuparan ng kanilang kahilingan sa pamamagitan ng pagiging isang mabuting Kristyano. Ang ginhawa at kapanatagan ng kaloobang natatamo nila sa pakikipagtunguhan kay Maria ay nagbubunsod sa kanila upang higit na manampalataya at maniwalang sa pamamagitan ng paggabay at patnubay ni Maria sa bawat paghiling nila, nagkakaroon sila ng positibong pag-asa sa buhay. Naniniwala silang ang bawat pagtawag nila sa Mahal na Ina na nilalangkapan ng pagkilos ay magkakaroon ng katuparan kung sila ay karapat-dapat sa kanilang hinihiling.

Nakita rin sa mga liham na higit na nangingibabaw ang liham ng mga kababaihan sa Ina ng Laging Saklolo sapagkat bilang isang babae, higit nilang naiuugnay ang kanilagn mga sarili kay Maria. Bilang mga babae rin, higit na mas madaling magpahayag sapagkat emosyonal ang mga kababaihan sa kanilang mga nadarama. Ang kanilang pagiging bukas sa lahat ng kanilang pinagdaraanan sa buhay kumpara sa mga lalaki ang dahilan kung kaya't higit na mas madalas lumiham ang mga babae sa Mahal na Birhen na kadalasan ay may himig ng pagsusumbong o paglalahad ng kanilang pinagdaraanan sa buhay. Ang pagiging totoo at makatotoo ng mga deboto sa Mahal na Ina ay nagpapakita ng kanilang tunay na debosyon.

(C) 2015 Jennifer M. Casabuena

http://www.kritike.org/journal/issue 17/casabuena december2015.pdf

ISSN 1908-7330

(cc) BY-NC-ND 
College of Education, Arts \& Sciences, De La Salle Lipa, Philippines

\section{References}

Aguas, Raymond B. Relating Faith and Political Action: Utopia in the Theology of Gustavo Gutierrez (Unpublished Ph.D. Dissertation, Indiana: University of Notre Dame, 2007).

Batalov, Eduard, The American Utopia (Moscow: Progress Publishers, 1985).

Catholic Bishop's Conference of the Philippines (CBCP), Catechism for Filipino Catholics (Manila: ECCCE Word \& Life Publications, 2008).

Demeterio, Feorillo Petronillo A., III, "Mga Anyo at antas ng Pag-asa na Nakapaloob sa mga Diskurso ng El Shaddai," in Malay, 22:2 (2010).

Geoghegan, Vincent, "Ideology and Utopia," in Journal of Political Ideologies, 9:2 (2004).

Manheim, Karl, Ideology and Utopia: An Introduction to the Sociology of Knowledge (London: Routledge and Kegan Paul, Ltd., 1960).

Sargent, Lyman T., "Ideology and Utopia: Karl Mannheim and Paul Ricoeur," in Journal of Political Ideologies, 13:3 (2008), 266-267.

"Utopianism," in Index, Vol. 10 of Routledge Encyclopedia of Philosophy, ed. By Edward Craig (London: Routledge, 1998).

(c) 2015 Jennifer M. Casabuena

http://www.kritike.org/journal/issue 17/casabuena december2015.pdf

ISSN 1908-7330

(cc) BY-NC-ND 